\title{
Green Knowledge in Teaching and Learning in Higher Education: Evidence from a South African University
}

\author{
Mabutho Sibanda \\ School of Accounting, Economics \& Finance \\ University of KwaZulu-Natal, South Africa \\ sibandam@ukzn.ac.za
}

\section{Doi:10.5901/mjss.2013.v4n3p709}

\begin{abstract}
A new phenomenon called "green knowledge" is fast developing in the modern economy albeit without responsive actions from management studies programmes offered by universities. Green knowledge refers to the awareness of climate change issues in everyday life. As much as business ethics has been given much attention in all spheres of academia, I argue that the expansion and adoption of green knowledge systems should be treated with urgency in institutions of higher education. The role of universities in societal transformation will thus lead to the appreciation of the consequences of climate change at grassroot level in modern society. This study therefore uses a survey technique to ascertain the use of green knowledge in teaching and learning among students in the College of Law and Management Studies at UKZN. A cluster comprising 225 students was used and a response rate of 58 percent was attained. The results show that students are conversant with climate change issues but do not engage themselves in green practices during teaching and learning for reasons such as the convenience of using printed materials, the high cost of electronic gadgets and resistance to change to newer techniques. Also the majority of the respondents support the idea of incorporating climate change issues in the university curricula although only 30 percent expressed a willingness to study a standalone module related to climate change. Finally, a green teaching and learning philosophy is proposed for higher education, which if adopted could lead to a green knowledge society.
\end{abstract}

Keywords: green knowledge, climate change, teaching and learning, higher education

\section{Introduction}

Environmental issues, and in particular climate change, have become topical in the modern economy. Related to this is the growing focus on a knowledge-driven economy where universities play a central role in societal transformation (Brennan, 2002). This transformation requires that universities offer programmes that are responsive and relevant to the demands of the new economy. Although universities offer environmental programmes, climate change issues go beyond science and engineering programmes to encompass a broad spectrum of academic programmes. As such, university curricula development should be dynamic and incorporate climate change issues in all programmes of study and develop what I refer to as "green knowledge". The concept of green knowledge is synonymous with the green knowledge economy, except that in this paper I refer to it as a pathway to establishing a green knowledge society. A green knowledge society is an expanded knowledge society that is conversant with global warming issues. Consequently, universities as role models for a transformative society should promote awareness and the establishment of green knowledge societies. This transformation should lead to sustainable business and work practices beyond obtaining a university qualification. This study focuses on the College of Law \& Management Studies at the University of KwaZuluNatal in South Africa.The College of Law and Management Studies consists of four schools, namely, School of Accounting, Economics and Finance; Graduate School of Business and Leadership; School of Management, Information Technology and Governance; and the School of Law. The College of Law and Management Studies handbook shows that the college offers three environment-related modules as electives at third-year level and honours level. The third-year module (Environmental Economics) has second-year economics as a prerequisite while the honours module requires an admission into the honours programme or econometrics or its equivalent at third-year level. Sustainable Resource Usage is another fourth-year module which deals with environmental issues. Given the scope and the requirements to study these three Economics modules, the question that arises pertains to the extent to which green knowledge acquired through university education can be used to transform society amid climate change concerns and the depletion of natural resources. This study therefore seeks to establish the awareness, and promotion of green knowledge in teaching and learning in the College of Law and Management Studies of which only schools in Management Studies are used in the 
survey. The study builds a case for incorporating climate change issues in all management studies programmes.

\section{Literature Review}

Teaching and learning in the green knowledge sphere of study requires that a lecturer develops materials for active learning. The materials should encompass developing disciplinary competence through modeling (Dison \& Pinto, 2000). According to Dison and Pinto, disciplinary competence is developed through both cognitive competence and linguistic competence which forms the first pedagogical principle. This is supported by Chickering's seven vectors of student development and student retention theories (Chickering, 1969; Jama, Mapesela, \& Beylefeld, 2008). The second principle is the promotion of language and learning competence in higher education. This according to Dison and Pinto (2000) requires appropriate support and structure to allow for diverse socio-cultural backgrounds. Thus in a teaching environment it is important to appreciate diversity and enable effective knowledge transfer (Abiddin \& Ismail, 2012; Gurin, Dey, Hurtado, \& Gurin, 2002; Pope, Reynolds, \& Mueller, 2004; Tennant, Mcmullen, \& Kaczynski, 2010; Valentine \& Taub, 1999). The understanding of these competencies and cultural backgrounds is likely to foster the development of green teaching and learning practices within the university community. This may be summarized as knowledge, comprehension, application, analysis, synthesis and evaluation of learning tasks (Dison and Pinto, 2000:169). The principles may be used to guide the development of a green teaching and learning philosophy. The third principle relates to the promotion of active student learning in class. This leads to interactive sessions and as such students learn from these interactions. Finally Dison and Pinto's fourth principle relates to the development of "higher-order skills and the ability to transfer knowledge and skills by means of explicit teaching methods" page 170. These four principles summarize in a nutshell how to synthesize green knowledge into university curricula. Given the nature of student understanding, and probably pre-higher education knowledge of green economics, university students are likely to comprehend and embrace the green knowledge concept.

Some scholars point to the role of universities and lecturers in developing critical thinking. It has been argued that universities have become knowledge-generating factories (Brennan, 2002) while it remains critical to model a student's understanding of learning in higher education (Prosser \& Trigwell, 1999). Prosser and Trigwell based their discussion on the earlier work called the presage-process-product model of learning and teaching (Biggs, 1978; Prosser, 1994) to develop a framework that requires teachers to be aware of their conceptions of teaching and learning and the promotion of a student-focused approach (Prosser \& Trigwell, 1999). This model of teaching allows students to be at the centre stage of an instructional session and as such promotes constitutionalist perspective that the individual and the learner are not independently constituted. On the other hand Prosser and Trigwell acknowledge the constructivist perspective that knowledge is acquired from within but driven by the external environment. Thus both the student-focused approach and the constructivist perspective may be used to model the green teaching and learning approach in that they both lead to knowledge generation.

Then again, college teaching paradigms have been changing over the past century. The old and new paradigms differ in the way students' involvement in the teaching process is construed (Campbell \& Smith, 1997). Campbell and Smith provide an insightful distinction between these paradigms, and as such newer paradigms may also be used in enhancing green knowledge acquisition in higher education. Over the past three decades active learning and experiential learning have been the main focus of enhancing effective teaching and learning in higher education (Fink, 2003). These two methods have been supported by contact-based teaching and learning centres. Among the methods of teaching that have been explored over the past two decades is the "role-playing, simulation, debate, and case studies" method (Bonwell \& Eison, 1991). The second one is the "writing to learn" method which enhances the effectiveness of student learning (Bean, 1996). Small group learning where temporary groups are created to form cooperative creative learning and team-based learning is a recommended teaching method as well (Johnson, Johnson, \& Smith, 1991; Michaelsen, Knight, \& Fink, 2002). These methods may also be used to incorporate green knowledge-based illustrations and demonstrations in class.

Another teaching method recommended by scholars is "assessment as learning" where classroom assessment is conducted and frequent feedback provided to enhance learning (Angelo \& Cross, 1993; Mentkowski, 1999). This method also assists teachers to evaluate the effectiveness of their teaching strategies. The other methods are "problem-based learning" and "service learning". The problem-based learning method provides students with critical thinking skills in solving real world problems (Duch, Groh, \& Allen, 2001). Students are provided with the problem and have to make preliminary analyses, collect data and propose a solution (Fink, 2003). With service learning students and the university are provided with an opportunity to engage with the community in a course-related activity (Rhoads \& Howard, 1998; 
Zlotkowski, 1998). This approach helps students understand community problems and hence fosters quality learning in the subject area. With climate change receiving much attention globally, students may be required to include climate change issues in problem solving and service learning activities, and subsequently drive a green knowledge society.

In addition, with the increased innovations in information communication technology (ICT) most higher education institutions are embracing even newer teaching and learning techniques. This is primarily so in most developed countries with sustainable infrastructure to support the systems. In most African countries the use of technology is limited mainly due to civil strife, lack of infrastructure, increased socioeconomic demands, etc. (Brennan, 2002; Cloete et al., 2002). This dimension to higher education teaching and learning leads to improved efficiencies within institutions. The advent of digital technology for education requires that teachers upgrade their skills to keep abreast of the ever-changing technological space (Tennant et al., 2010). Not only are teachers required to upgrade their skills but there is growing competition for online students and the use of e-learning in most higher education institutions (Fink, 2003; Tennant et al., 2010). However, benefits reaped from e-learning have been found to outweigh challenges in higher education (Mouyabi, 2011). Mouyabi used the Moodle online learning platform as a case for the use of e-learning in higher education. Moodle is a free open source Virtual Learning Environment and stands for Modular Object-Oriented Dynamic Learning Environment. Mouyabi argues that ICT should be used as a tool to enhance face-to-face instruction in higher education. Online interactivity also enhances critical thinking and reflection, and promotes participation (Picard, Wilkinson, \& Wirthensohn, 2011; Vallance, 2008; Yang, Newby, \& Bill, 2008). A major problem in South African universities arises when dealing with English second-language students especially those from economically disadvantaged families. These students may have difficulties in grasping web-based applications and vocabulary used in the e-learning platforms (Nel \& Dreyer, 2005). Interactive technologies have impacted on teaching and learning in higher education world-wide. Thus the advent of ICT has created new learning environments and increased faculty roles in designing and managing the new environment (Bass, 2000). The use of ICT can be classified as green teaching and learning as it reduces the use of printed material although the debate as to which method is greener continues.

The literature discussed thus far provides the impetus for green teaching and learning in higher education institutions. Most of the teaching techniques discussed are still applied in modern teaching practice although newer models are becoming popular especially with the advent of innovations in information communication technology over the past decade. The use of online or digital teaching techniques is prevalent in modern teaching and learning. However, the applicability of some teaching techniques in the quest for green knowledge remains debatable. I find the use of ICT intriguing in green knowledge teaching. The next section discusses the data collection method employed in this study and how the data was processed, analyzed and interpreted.

\section{Materials and Methods}

The study uses a questionnaire to ascertain the level of green knowledge awareness among students in the College of Law and Management Studies at the University of KwaZulu-Natal. The population under consideration includes all registered students in the college. A cluster sampling technique is used to select a group of students for the study. Clusters are created in the form of lecture blocks from third-year modules. I choose the third-year students because they have become acquainted with the university system and have a broader understanding of university education. Each lecture class/module forms a cluster. A cluster comprising third-year finance students was selected. These finance students major in finance and or economics, marketing, supply chain and management programmes, making the cluster diverse. This cluster had 225 registered students attending lectures in a single venue twice a week during the first semester. A structured questionnaire comprising twelve questions was used in the survey. The questions are divided into four groups consisting of (i) demographics; (ii) green knowledge practices in teaching and learning; (iii) green knowledge awareness in teaching and learning; and (iv) incorporating green knowledge into university curricula. The frequency distribution is used to analyze the data as measured by relative frequency $=\frac{f}{n}$, where $f$ is the frequency and $n$ is the total number of observations. The Chi-Square technique is then used to test the significance of the association between paired variables and is calculated as:

$$
\text { Chi-square }=: \chi^{2}=\sum \frac{(\text { Observed }- \text { Expected })^{2}}{\text { Expected }}
$$

where the Expected $=\frac{\text { row total } \times \text { column total }}{\text { grand total }}$ since the study uses yes or no responses in the questionnaire. This enables the analysis of two different variables and whether those variables are associated with each other (Walker, 2010). The null hypotheses for the study are as follows:

$\mathrm{H} 1$ : There is no significant association between age and attitude towards green knowledge practices. 

education.

$\mathrm{H} 2$ : There is no significant association between climate change awareness and the medium of study in higher

H3: There is no significant association between climate change awareness and attitude towards incorporating climate change into university curricula.

$\mathrm{H} 4$ : There is no significant association between incorporating climate change in university curricula and societal transformative role played by universities.

\section{Results and discussion}

\subsection{Response rate and demographics of the sample}

A sample of 225 third-year students was used in the survey. Of the student population sampled, only 131 responded to the survey representing a 58 percent response rate. The low response rate is supported by a comparative study which found an average rate of response of 57.6 percent in the education sector (Baruch, 1999). The reasons for this relatively low response rate were due to absenteeism and lack of interest in the survey. All the respondents surveyed were full-time students at the University of KwaZulu-Natal, South Africa in 2013. Of the respondents, 67 percent were 21 years or older and 33 percent were under 21 years of age. Age is important in this study as it may impact on the medium of study and attitude towards green knowledge practices.

\subsection{Green knowledge practices in teaching and learning}

In testing for the use of green knowledge practices in teaching and learning, students were required to respond to questions relating to the use of technology and conventional methods during lecture deliveries and self-study. Concerning the preferred medium of study, 89 percent of the respondents showed that they preferred printed material to electronic material. All respondents participated in this question. Reasons for opting for printed instead of electronic material vary from access and convenience to expenditure related to purchasing electronic devices. The majority of students rely on the university computer network and as such electronic media is not always accessible to them. Related to this is the method for distributing teaching material such as lecture notes and handouts. Of the total respondents, 78 percent prefer printed to the electronic distribution of teaching material. Only 22 percent prefer the use of the university learning website (e-learning) and Moodle sites. One reason provided for this preference is that printed material has always been used in the past, which suggests that students resist change. In contrast to Mouyabi (2011), the results show that most students seem to prefer printed material to an ICT-driven medium of learning. The results are however supported by assertions made by Nel and Dreyer (2005) that students may have difficulties in grasping web-based applications. Of the 70 percent of the students who indicated green practice in daily living, 31 percent were under 21 years of age while 69 percent were over 21 years old. Of those who answered no, 31 percent were also under 21 years and the balance over 21 years. Testing the association between age and attitude towards green knowledge practices a $x^{2}$ value of 0.021 and a $p$-value of 0.885 was obtained. Since the $p$-value is greater than 0.05 , the null hypothesis that there is no significant association between age and attitude towards green knowledge practices is not rejected. Hence there is no evidence suggesting that age and green knowledge practices are associated among university students. Furthermore, of the 96 percent who showed awareness of climate change in general, 72 percent indicated green knowledge practices. To test whether climate change awareness is associated with green practices, an $x^{2}$ value of 6.056 and a $p$-value of 0.014 were obtained suggesting that the test is significant at 5 percent. Consequently, we conclude that in spite of the lack of a significant association between age and attitude towards green practices, climate change awareness impacts on green knowledge practices among university students.

\subsection{Green knowledge awareness in teaching and learning}

The majority of the respondents (70 percent) showed awareness of climate change issues relating to the use of electrical gadgets in everyday life. However, only a response rate of 55.5 percent participated in this particular question. This is slightly lower than the average response rate of 57.6 percent for the education sector found by Baruch (1999). Most of these respondents acknowledged that the excessive or unnecessary use of electricity impacted negatively on the planet. However, 30 percent of the respondents expressed ignorance about the effect of electricity consumption on the planet, which should be of major concern to society. Besides the effect of electricity consumption on the planet, this has adverse 
effects on the national grid and personal finances. Relating to the awareness and meaning of the term "green knowledge economy", 66 percent of the respondents answered yes while 34 percent answered no. All the 131 respondents participated in this question. The tests of significance between age and the mode of distributing teaching material and lecture visuals were both statistically insignificant at 5 percent level. All respondents less than 21 years old (33 percent of respondents) preferred the use of printed material in teaching and learning, while of those aged 21 year and more, 82 percent prefer printed material. Only 18 percent of the age group of 21 years and more prefer electronic teaching and learning material. The $x^{2}$ value of 8.847 and a $p$-value of 0.004 are obtained. Since the $p$-value is less than tan 0.05 , the null hypothesis that age does not impact on the medium of study is rejected. This suggests that student age determines the preference of medium of study. Of the 96 percent of the respondents who asserted a knowledge of climate change, 88 percent preferred printed teaching and learning material, while all respondents (4 percent) who answered no to climate change awareness also preferred printed to electronic material for self-study. However, an $x^{2}$ value of 0.678 and a $p$ value of 0.410 suggest that the test is not significant. Thus climate change knowledge does not explain the material preference for self-study. Similarly, an insignificant $X^{2}$ value between climate change awareness and teaching and learning material distribution of 1.478 and a $p$-value of 0.224 supports student preference for printed over electronic material for self-study. However, of the 96 percent who showed climate change awareness, 77 percent preferred the use of data projector (power-point slides) to overhead transparences. The Chi-Square for this association was 8.294 with a $p$ value of 0.004 suggesting the test is significant. As such the null hypothesis that there is no significant association between climate change awareness and lecture visuals is rejected at 5 percent significance level.

\subsection{Incorporating green knowledge into university curricula}

Incorporating climate change issues into the university curricula is another way of improving awareness and green teaching and learning practices among university students. Subsequently, these students would transfer green knowledge to society thus leading to a green knowledge society. This is the transformative role as suggested by Brennan (2002). The majority of the respondents (82 percent) view climate change as an area that should be taught at universities. However, only 56 percent of the respondents expressed willingness to study a module relating to climate change or environmental economics. Related to this, only 30 percent of the respondents were of the view that a module related to climate change should be made compulsory in all programmes of study at university, while the balance of 70 percent viewed it otherwise. Although most students are of the view that climate change issues should be taught at university, only a few of them are willing to enroll for such a module. However, appreciation of the term "green knowledge economy" does not have any significant association with age. The $\chi^{2}$ value is 0.687 with a $p$-value of 0.407 . Also, of the 96 percent of respondents who showed awareness of climate change issues, 97 percent were of the view that climate change should be given considerable attention in society. The association has $x^{2}$ value of 2.828 with a $p$-value of 0.093 . Thus the test is insignificant at a 5 percent level. Similarly, Chi-Square tests show insignificant associations between climate change awareness and preparedness to study a module related to climate change or making a climate change module compulsory for all programmes of study in higher education. Consequently we conclude that there is no significant association between climate change awareness and the attitude towards incorporating climate change into the university curricula, and we reject the null hypothesis $\mathrm{H} 4$. However, of the 82 percent that feel climate change should be included in the university curricula, 75 percent prefer printed material to web-based resources. Furthermore, the association between these two variables is statistically insignificant at 5 percent level with $x^{2}$ value 2.924 and $p$-value of 0.087 which is greater than 0.05 .

On the other hand, I find a significant association between incorporating climate change into the university curricula and the need to promote climate change awareness in society. Thus, of the 82 percent respondents who feel climate change should be incorporated into higher education curricula, 84 percent are of the view that climate change issues should be promoted in society. The association is statistically significant at 5 percent with $\chi^{2}$ value of 4.572 and $p$-value of 0.032 which is less than 0.05 . However, of the 85 percent respondents who feel climate change issues should be incorporated into higher education curricula, 63 percent expressed the willingness to study a module related to climate change. Conversely, of the 85 percent who feel climate change should be incorporated into higher education curricula, 37 percent expressed unwillingness to study a module related to climate change. Furthermore, of those that feel climate change should not be incorporated into higher education curricula, 84 percent expressed unwillingness to study such content in their programmes of specialization. The association between incorporating climate change in higher education and preparedness to study a climate change-related module is significant at 5 percent with $\chi^{2}$ value of 14.703 and $p$-value of 0.0000 . Consequently, we reject the null hypothesis and conclude that students were not all the same in viewing 
climate change and its incorporation into higher education curricula: some students were more likely to express willingness to study climate change-related modules than others.

\section{Green teaching and learning philosophy}

The green teaching and learning philosophy proposed in this study entails the use of a number of teaching and learning techniques. These include the use of ICT as a medium of self-study and material distribution. Moreover, the approach requires the incorporation of green knowledge techniques in modules offered by the college. These techniques may be in the form of examples or subsections of the module content. Incorporating green knowledge into all third-year modules for example, will enable the students to transfer that green knowledge to society. These practices should result in a green knowledge society as university graduates have the ability to transform societies. Incorporating climate change into the curricula may take the form of introducing new modules in climate change within existing programmes; including a climate change module or programme or simply using examples and illustrations that support green practices during lectures or in the course material. Such practices could lead to the development of disciplinary competencies that are fused with green knowledge practices.

\section{Conclusion}

This study seeks to establish climate change awareness and the use of green teaching and learning practices among university students. A combination of teaching and learning techniques is explored and used to develop a green teaching and learning philosophy. A sample of 225 third-year students was used in the study and a response rate of 58 percent was attained. The study found that the majority of students are conversant with climate change issues and as such their routine activities in and outside the classroom are "green" (environmentally conscious). However, the study finds that the majority of students prefer printed material to electronic material for teaching and learning. The impact of printed material on climate change during teaching and learning is found to be statistically insignificant. Furthermore, the respondents support the idea of introducing climate change modules at universities although only a minority is willing to enroll for such a module. As such, results show that although students show awareness of climate change issues in general, they do not practice green teaching and learning techniques at university. Finally, a green teaching and learning philosophy is developed where teaching and learning encompasses both the use of technology and conventional methods. A major hindrance to green teaching and learning is identified as the high cost of electronic gadgets.

\section{Recommendations}

The university should consider implementing the following recommendations in order to promote sustainable teaching and learning practices within the College of Law and Management Studies:

1. Introducing a module that focuses on green knowledge systems at undergraduate level.

2. Introduce an elective module that covers climate change at postgraduate level.

3. Consider incorporating the cost of mini-tablets into the fee structure and make the gadgets available to students at a certain level of study.

4. Encourage the academic teaching staff to use environmentally friendly teaching methods and constantly promote the use of ICT in lectures.

5. Encourage teaching and learning material developers, including publishers, to incorporate climate change examples, exercises and case studies as part of the content.

\section{References}

Abiddin, N.Z., \& Ismail, A. (2012). Exploring Student Development Theory in Enhancing Learning through Supervision. International Journal of Academic Research in Progressive Education and Development, 1(1), 213-223.

Angelo, T. A, \& Cross, K.P. (1993). Classroom Assessment Techniques: A Handbook for College Teachers (2nd ed.). San Fransisco: Jossey-Bass.

Baruch, Y. (1999). Response Rate in Academic Studies-A Comparative Analysis. Human Relations., 52, 421-438.

Bass, R. J. (2000). Technology, Evaluation, and the Visibility of Teaching and Learning. In K. E. Ryan (Ed.), Evaluating Teaching in Higher Education: A vision for the future (pp. 35-50). United States of America: Jossey-Bass Inc.

Bean, J.C. (1996). Emerging Ideas: The Professors' Guide to Integrating Writing, Critical Thinking, and Active Learning in the Classroom. San Francisco: Jossey-Bass. 
Biggs, J.B. (1978). Individual and group differences in study process. British Journal of Education Psychology, 48, 266-279.

Bonwell, C. G, \& Eison, J. A. (1991). Active Learning: Creative excitement in the class room ASHE-ERIC Higher Education Report 1. Washington, D.C: George Washington University

Brennan, J. (2002). Transformation or Reproduction. In J. Enders \& O. Fulton (Eds.), Higher Education in a Globalising World: International Trends and Mutual Observations. Dordtrecht: Kluwer Academic Publishers.

Campbell, W. E, \& Smith, K. A. (1997). New Paradigms for College Teaching. Edna, Minn: Interaction Book Company.

Chickering, A. W. (1969). Education and Identity. San Francisco: Jossey-Bass.

Cloete, N, Fehnel, R, Maassen, P, Moja, T, Perold, H, \& Gibbon, T (Eds.). (2002). Tranformation in Higher Education: Global Pressures and Local Realities in South Africa. Lansdowne: Juta and Company.

Dison, L, \& Pinto, D. (2000). Developing Materials for Active Learning. In S. Makoni (Ed.), Improving Teaching and Learning in Higher Education: A Handbook for Southern Africa. Johannesburg: Witwatersrand University Press.

Duch, B. J, Groh, S. E, \& Allen, D. E (Eds.). (2001). The Power of Problem-Based Learning. Sterling: Va.: Stylus.

Fink, L.D. (2003). Creating Significant Learning Experiences: An integrated approach to designing college courses. United States of America: John Wiley \& Sons, Inc.

Gurin, P, Dey, E. L, Hurtado, S, \& Gurin, G. (2002). Diversity and Higher Education: Theory and Impact on educational Outcomes. Harvard Educational Review, 72(3), 330-366.

Jama, M. P, Mapesela, M. L. E, \& Beylefeld, A. A. (2008). Theorectical perspectives on factors affecting the academic performance of students. South African Journal of Higher Education, 22(5), 992-1005.

Johnson, D.W, Johnson, R.T, \& Smith, K.A. (1991). Cooperative learning: Increasing College Faculty Instructional Productivity. Washington, D.C: ASHE-ERIC Higher Education Reports, No 4.

Mentkowski, M. (1999). Learning that Lasts. San Fransisco: Jossey-Bass.

Michaelsen, L. K, Knight, A. B, \& Fink, L. D. (2002). Team-Based Learning: A Transformative Use of Small Groups for Large and Small Classes. Westport, Conn: Bergin \& Garvey.

Mouyabi, J. S. M. (2011). Higher Education in the wake of new ICT: Reaping benefits or creating more problems through e-learning. South African Journal of Higher Education, 25(6), 1178-1090.

Nel, C, \& Dreyer, C. (2005). Factors predicting English second-language students' use of web-based information systems: Implications for student support. South African Journal of Higher Education, 19(1), 129-143.

Picard, M. Y, Wilkinson, K, \& Wirthensohn, M. (2011). An online learning space facilitating supervision pedagogies in science. South African Journal of Higher Education, 25(5), 954-971.

Pope, R., Reynolds, A., \& Mueller, J. (2004). Multicutural competence in student affairs. San Francisco: Jossey-Bass.

Prosser, M. (1994). A phenomenographic study of students' intuitive and conceptual understanding of certain electrical phenomena. Instructional Science, 22, 189-205.

Prosser, M, \& Trigwell, K. (1999). Understanding Learning and Teaching: The Experience in Higher Education. Great Britain: SRHE and Open University Press.

Rhoads, R. A, \& Howard, J. P. F. (1998). Academic Service Learning: A Pedagogy of Action and Reflection. San Fransisco: JosseyBass.

Tennant, M, Mcmullen, C, \& Kaczynski, D. (2010). Teaching, learning and research in Higher Education: A critical approach. New York: Routledge.

Valentine, J.J., \& Taub, D.J. (1999). Responding to the developmental needs of student athletes. Journal of College Counselling, 2, 164179.

Vallance, M. (2008). Using a database application to support reflective practice. TechTrends: Linking research and practice to improve learning, 52(6), 69-74.

Walker, I. (2010). Research Methods and Statistics. Great Britain: Palgrave Macmillan.

Yang, Y.T. C, Newby, T, \& Bill, R. (2008). Facilitating intercations through structured web-based bulletin boards: A quasi-experimental study on promoting learners' critical thinking skills. Computers and Education, 50(4), 1572-1585.

Zlotkowski, E (Ed.). (1998). Successful Service-Learning Programmes: New Models of Excellence in Higher Education. Bolton, Mass: Anker. 
